\title{
An Experimental Evaluation of the Effectiveness of Beach Ashtrays in Preventing Marine Contamination
}

\author{
Walter Martin Widmer* and Rodrigo Arantes Reis \\ Universidade Federal do Paraná; Rua Jaguariaíva, 512; Matinhos - PR - Brasil
}

\begin{abstract}
In this study, hypotheses concerning the use of beach ashtrays were experimentally tested. Results indicated that the mean rate of abandonment of this equipment was low (1.5\%). The mean amount of cigarette stubs (3.4 items/ashtray) was greater than mean amounts of other types of litter. People with different socioeconomic profiles had different perceptions regarding the issues associated with beach debris. These results indicated that beach ashtrays could be useful to prevent the contamination of these environments and that differences in socioeconomic characteristics of beachgoers could partially explain the differences in perceptions regarding the presence of waste on the beaches. This information could now be used by coastal managers to plan strategies to reduce the marine contamination.
\end{abstract}

Key words: Beach, Brazil, cigarette butts, coastal management, marine debris, Paraná

\section{INTRODUCTION}

Several studies have indicated that sandy beaches are typically contaminated with man-made debris (Corbin and Singh, 1993; Williams and Nelson, 1997). This contamination is considered to be a threat to beach tourism, since it is visually unpleasant. In addition, debris can risk the health and safety of beachgoers. Many human activities are considered to be potential sources of debris found on the beaches. Fishing, recreational boating and merchant shipping are examples of human activities that contribute to the presence of debris in the marine environment, which can be transported to sandy beaches by currents and tides. On land, poor collection and disposal of municipal solid wastes can also allow debris to enter rivers, creeks or water channels, which may ultimately transport these items to the beaches and other coastal environments, such as mangrove forests (Cordeiro and Costa, 2007) and submerged benthic environments (Widmer, 2004).

Marine debris information regarding Latin America and the Wider Caribbean Region was reviewed by Ivar do Sul and Costa (2007). Among other findings, they stressed that Latin America region was still little studied, given the magnitude of the problem of debris on the marine environment. In Brazil, most of the studies about marine debris have investigated the presence of anthropogenic debris on sandy beaches, probably because beaches are relatively easy to access and are important recreational destinations. In a study on the Island of Santa Catarina, where the city of Florianópolis is located, Widmer et al. (2004) found that plastics, most of them from local sources, were the main contaminants of those beach environments. Wetzel et al. (2004) found

*Author for correspondence: walterw@ufpr.br 
that litter accumulated around urbanized areas of Cassino beach were very high, when compared to other studies worldwide. In this same beach, Santos et al. (2003) performed an investigation about people's perceptions regarding beach debris and found that people perceived that a solution for reducing the problem of beach debris involved the allocation of more trash bins on beaches.

People frequenting beaches are also a significant source of debris (Madzena and Lasiak, 1997, Silva-Iniguez and Fisher, 2003). Plastic bags, toys, glass bottles and aluminum cans are examples of litter items that people leave on beaches. Cigarette stubs found on beaches are visually unpleasant and associated with an unhealthy habit. Considering that 4.5 trillion filtered cigarettes were produced worldwide in 1995, it was reasonable that a large number of them would end up in oceans. In fact, for a continuous period of eight years (19901997), cigarette stubs have been the leading item found during the International Coastal Cleanup project (Novotny and Zhao, 1999). The origin of cigarette stubs was considered by Tudor and Williams (2004) to be "very likely" from beach users. Cigarette butts were among the most abundant residues generated by beach visitors at Cassino beach in southern Brazil (Santos et al., 2005). Cigarette stubs and some other objects, such as glass fragments, are too small to be collected by the municipality cleaning staff and, in comparison to aluminum cans, hold no current recycling value and, therefore, are not targeted by people that search beaches for recyclable materials.

The typical managerial action that municipalities adopt in order to deal with the problem of marine debris on beaches is to allocate staff and resources (in some cases including purpose-built equipment) in order to periodically clean up the beaches. On the long term, it has been stressed to educate the beachgoers about the importance of reducing the amount of garbage on beaches and to prevent the debris to enter storm water drainage systems that will ultimately transport the debris to the marine environment, including beaches.

For small litter items, which are not typically collected by cleaning staff, portable beach ashtrays (PBA) may be suitable to deal with the problem of beach debris. These are devices intended to receive and store cigarette stubs and other small litter items generated by beach users (Fig 1). There are several models, displaying different shapes and made from different materials. The model used in this study was made of recycled plastic, with a pyramidal shape, measuring $15 \mathrm{~cm}$ in the longer axis. Its toping lid was a square, with each side 5 $\mathrm{cm}$. On the sides of the aperture there were two indentations designed to hold the cigarettes. It was meant to be partially inserted into the sand. An artwork for advertising could be printed over the outer side of the top lid. In Brazil, the selling price of each unit would be approximately US $\$ 1$ and the manufacturer of the PBA used in this study was CleanBeach Ltda., Porto Alegre, Brazil. Apparently, the use of these devices was increasing, since this company alone claimed to have increased its production capacity to 200,000 units per month (CleanBeach, 2009).

Although common sense suggests that PBA can be an effective tool to tackle the problem of beach debris, no formal documented evaluation of its effectiveness is known. Adaptive coastal management suggests that managerial initiatives should be framed as experiments in order to be tested (Underwood, 1998; Widmer, 2009). Therefore, inherent to the distribution of PBA on the beaches would be the expectation that such equipment will actually help reducing the amount of cigarette stubs on beaches and that the PBA itself will not become litter on the beaches. Therefore, the aim of this work was to study the effectiveness of PBA as a potential tool to reduce the contamination of beaches and to access beachgoers perceptions and attitudes towards beach debris. Specifically, three hypotheses were tested:

H1: Due to the intense use of some Brazilian beaches during summer, promotional material (such as hand-fans and leaflets intended to promote the environmental education) were distributed to beachgoers. It has been observed, however, that this material was sometimes left on the beaches, increasing the amount of debris already present on the beach. The model proposed was that this was a general pattern happening also in regards to PBA. Therefore, one would expect to find many PBA abandoned on the beach after the distribution of such material. For the purpose of hypothesis testing, the term "many" was here arbitrarily defined as being more than $5 \%$ of the PBA distributed. 


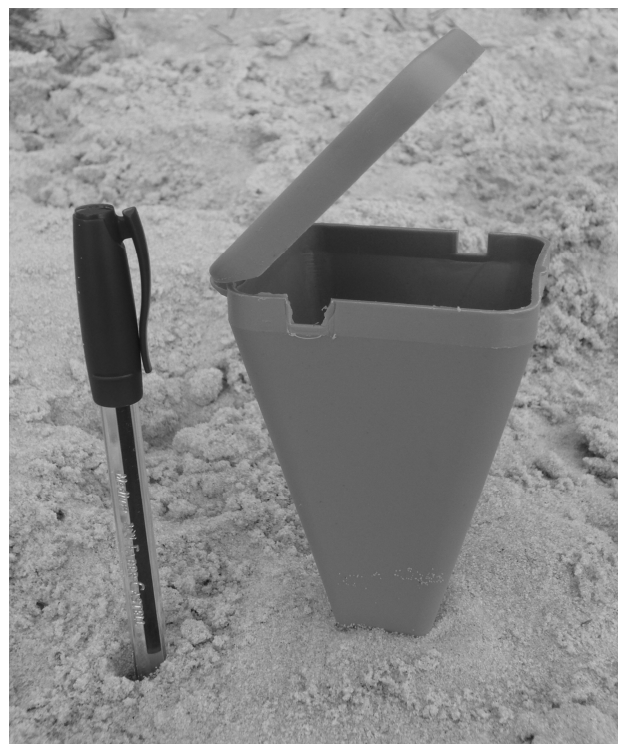

Figure 1 - Portable beach ashtray (PBA) used in this study. A pen was added on the left of the photograph for scale interpretation.

H2: Cigarette stubs are one item of litter commonly found on the beaches. PBA are said to be an effective tool to reduce the amount of these items on beaches. If this model was valid, one would expect to find a large proportion of cigarette stubs forming the contents of used PBA that were representatively sampled. In this study, "a large proportion" was defined as being greater than $50 \%$ of the total amount of items.

H3: Socioeconomic characteristics are known to affect people's perceptions and attitudes toward beach debris (Santos et al., 2005). If this was a general model, it would also be valid for Paraná beaches. Therefore, one would expect to find different perceptions and attitudes about beach debris and other environmental issues relative to socioeconomic characteristics of sampled beachgoers.

\section{METHODS}

The above mentioned hypotheses were tested in the coastal zone of the Brazilian state of Paraná. The Paraná coast is the second shortest coast among Brazilian states. However, it has economical significance due to the presence of Paranaguá Port, an important port for the Brazilian economy. In recent decades, there has also been a rapid process of urbanization associated with intense fluxes of tourists during summer seasons. The Paraná coastal plain is one geomorphological unit formed during transgressive-regressive cycles in the Quaternary, where the presence of estuarine systems (Paranaguá Bay and Guaratuba Bay) and beaches are highlighted (Angulo, 2004).

The beaches selected for this study were (i) Mansa beach, in the municipality of Matinhos; and (ii) Ipanema beach, in the municipality of Pontal do Paraná (Fig. 2). Mansa beach is approximately $1,200 \mathrm{~m}$ long and is directly influenced by the dynamics of Guaratuba Bay. Ipanema Beach is a stretch of approximately $1 \mathrm{~km}$ long of a $30 \mathrm{~km}$ long beach arch, with a direct oceanic influence. These beaches were selected because preliminary observations suggested that they were intensely used by beachgoers and that these beaches were visited by people with distinct socioeconomic profiles.

The distribution of PBA was done from $10 /$ January 2006 to $03 /$ February 2007 , on the afternoons of 15 days that included working days and weekends. Each day, two research assistants distributed approximately 100 PBA on a single beach. People were haphazardly chosen on the beach, the only criterion being persons older than 18 years of age. Approaching beach users was done by informing them that the distribution of PBA was part of a research and outreach project. Beachgoers were informed that by the time they 
would leave the beach, they could empty their PBA with the research assistant team that stayed in a solar tent on the beach. Beach users were also asked about being briefly interviewed, which, in case of acceptance, was performed for less than 10 minutes.

Interviews used open and closed questions that assessed beachgoers perceptions about environmental problems of the beach, about the specific problem of marine debris, its sources and the role of beach users as a source of debris. In addition, basic socioeconomic aspects were asked, such as place of permanent residency, gender, age, level of formal education, level of income and whether the beach user was smoker or not. The answers were recorded in paper sheets that were brought to the laboratory. Answers to open questions were coded into categories and then all answers were transferred to electronic data sheets. Research assistants visually searched the beach looking for abandoned PBA. This was done at 6
PM on every day when PBA were offered to beachgoers. The team walked $500 \mathrm{~m}$ on each side of the solar tent and registered in a field form the number of PBA retrieved. The possibility that research assistants would not see the abandoned PBA in the searching area was considered to be small, because PBA were conspicuous items (i.e., they were big, colorful and easily identifiable).

The contents of used PBA that were brought by the beachgoers by the time they left the beach were kept in plastic bags, which were brought to the laboratory, where they were sorted, photographed and finally disposed of in an appropriate manner. Data was recorded in paper datasheets which were transferred into electronic datasheets. Ten percent of all paper datasheets (interviews, abandoned PBA and contents of used PBA) were randomly selected and checked by two persons other than those that typed the data, as a quality control procedure.

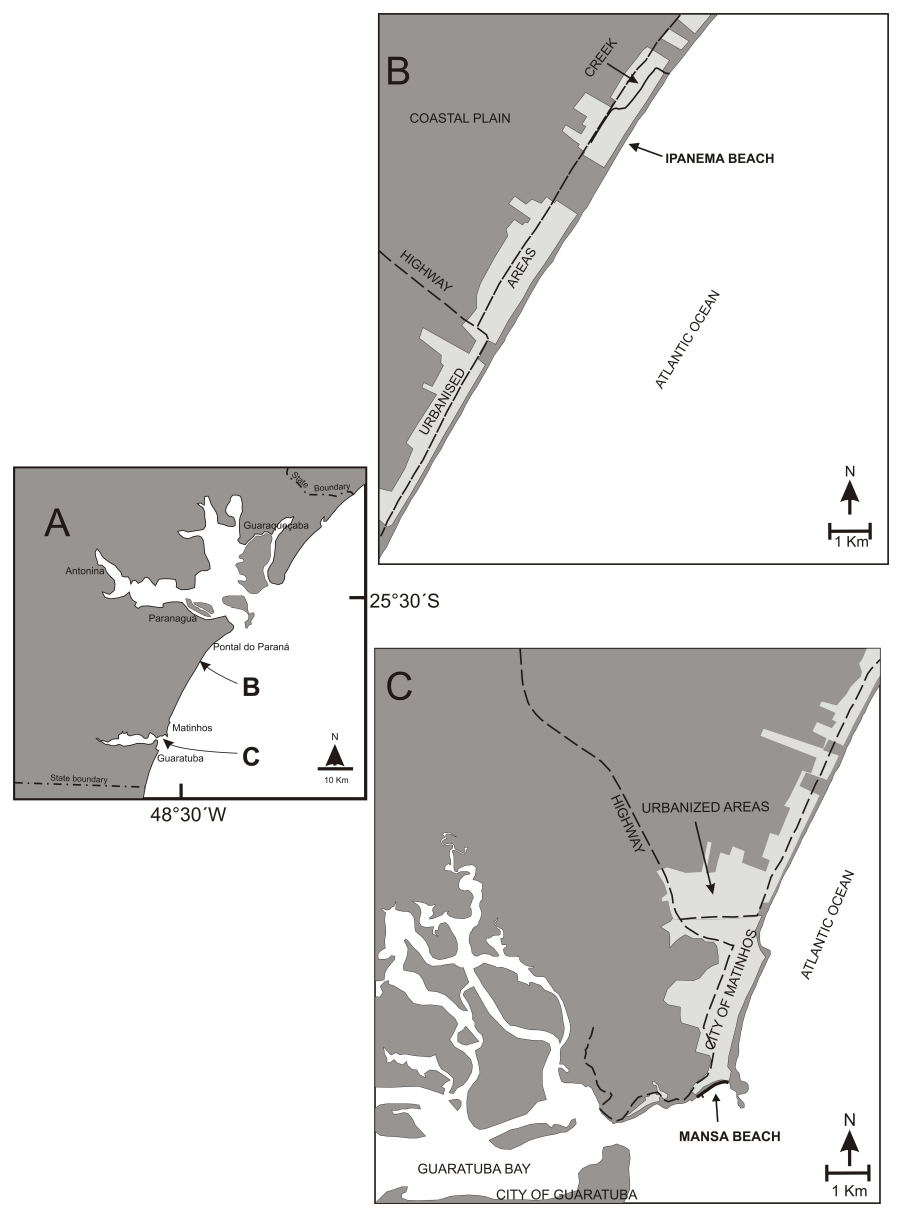

Figure 2 - Location of the study area. (a) The coast of Paraná state. (b) Ipanema beach and (c) Mansa beach. 
For H1, the percentage of PBA found abandoned on the beach out of the amount of PBA distributed every day was calculated and the null hypothesis that the resulting mean was less or equal to $5 \%$ was tested using Student's $t$-test. The null hypothesis $(\mathrm{H} 2)$ that the percentage of cigarette stubs was less or equal $50 \%$ was also tested using Student's $t$-test. Differences in the mean abundances of categories of litter found on retrieved PBA were tested using one-way Analysis of Variance (ANOVA). For this test, to ensure the independence of data, contents of each retrieved PBA were used in the analysis for just one category of litter. The assumption of homogeneity of variances was tested using Cochran's test. If a factor was found to be statistically significant ( $\mathrm{p}<$ 0.05), multiple comparisons (SNK tests) were used to test for differences between the levels within that factor (Underwood, 1997). If the assumptions of normal distributions were not met, nonparametric methods (one-sample Sign test and Wilcoxon-Mann-Whitney test) were used (Byrkit, 1987). Questionnaire answers were analyzed using chi-square test.

\section{RESULTS}

\section{Abandonment of PBA}

After the distribution of 1,448 PBA to the beachgoers during 15 days, a total of 22 PBA were found abandoned on the beach. In one day, the abandonment rate was 5\%. On the other 14 days, the abandonment rate was smaller than 5\%. The average abandonment rate was $1.49 \%( \pm \mathrm{SE}=$
$0.39 \% ; n=15)$. The median of the sampling distribution was $1.25 \%$ and it was not significantly greater than a median of 5\% (one-sample Sign test).

The mean percentage of abandonment in Mansa beach was $2.17 \%( \pm \mathrm{SE}=0.57 \% ; n=8)$, with median $=2 \%$, whereas in Ipanema beach the average abandonment rate was $0.71 \%( \pm \mathrm{SE}=$ $0.36 \% ; n=7)$, with median $=0$. This difference was not, however, significantly different (Wilcoxon-Mann-Whitney test, $U=11.5 ; \mathrm{p}>$ $0.05)$.

\section{Cigarette Stubs in PBA}

A total of 1,101 litter items were observed in the 168 PBA analyzed. On average, each PBA stored 6.55 items $( \pm \mathrm{SE}=0.51 ; n=168)$. The mean percentage of cigarette stubs in relation to the total amount of litter items present inside PBA was $46.7 \%( \pm \mathrm{SE}=3.3 \% ; n=168)$, with a median $=$ $50 \%$. There were $75 \mathrm{PBA}$ where the percentage of cigarette stubs was higher than $50 \%$. This pattern was not consistent with a hypothesized median value greater than $50 \%$ (one-sample Sign test). However, cigarette stubs were the most frequent type of litter item observed in the PBA analyzed. ANOVA test indicated that the mean abundance of cigarette stubs was significantly larger than the mean abundances of other categories of litter (Table 1, Figs. 3 and 4). No significant difference was found between the median percentages of cigarette stubs present in PBA deriving from the two beaches studied (Wilcoxon-Mann-Whitney test for large samples; $Z^{*}=-0.11 ; p>0.05$ ).

Table 1 - Analysis of Variance of mean abundances of categories of litter items found inside PBA used in Paraná beaches".

\begin{tabular}{ccccc}
\hline Source of Variation & Sum of Squares & D.F. & F & $\boldsymbol{p}$ \\
\hline Factor "categories of beach debris" & 1385.2 & 6 & 36.1 & $<0.001$ \\
Residual & 7458.9 & 1169 & & \\
Total & 8844.2 & 1175 & & \\
\hline
\end{tabular}

*Cochran's C $=0.7$ ( $\mathrm{p}<0.01)$. Data were not transformed, because no transformation removed heterogeneity of variances. This is considered acceptable for large, balanced designs (Underwood 1997, p. 193). 


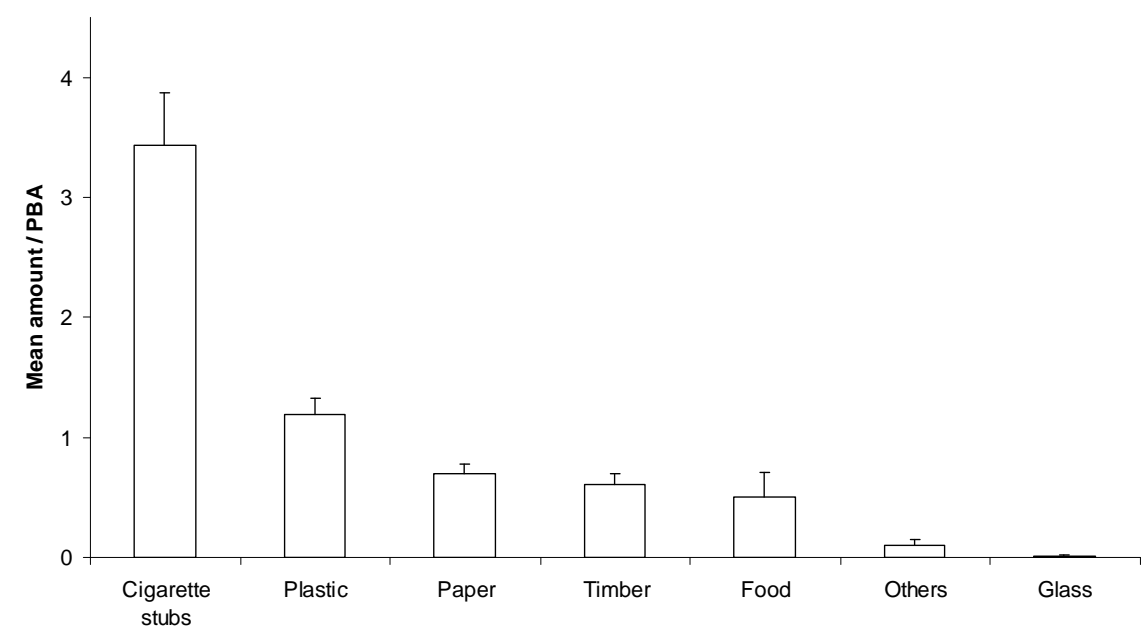

Figure 3 - Mean (+S.E.) amount of litter items per PBA used in Paraná beaches. N=168. The mean abundance of cigarette stubs is greater than other mean abundances, which were not significantly different from each other (SNK tests).

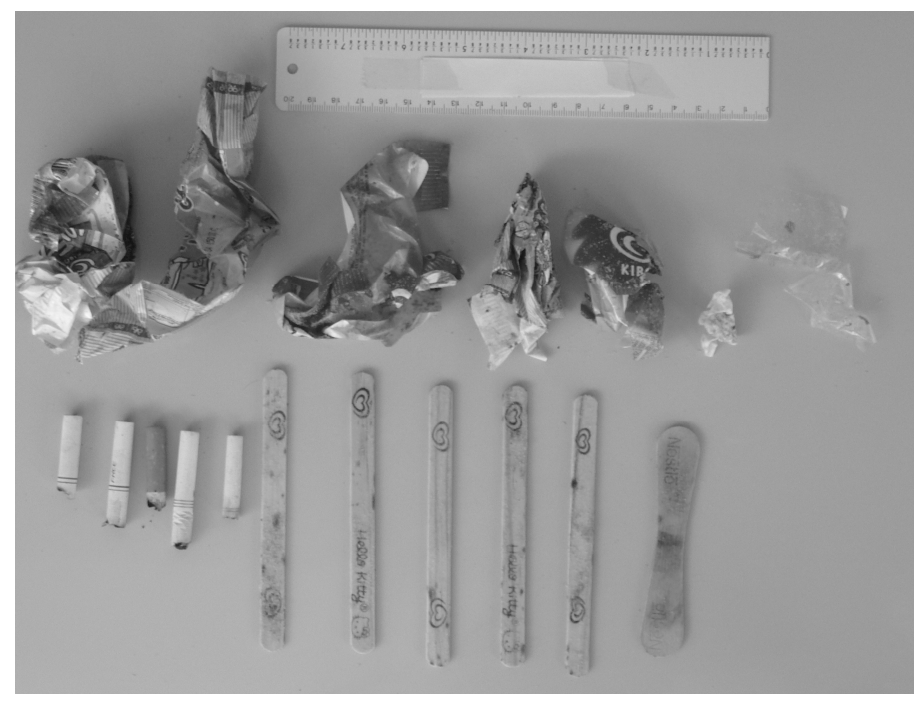

Figure 4 - Example of contents of one used PBA (the ruler was added for scale interpretation).

\section{Perceptions of beach visitors regarding solid waste contamination}

A total of 1,014 people on both the beaches were interviewed, being 468 from Mansa beach and 546 from Ipanema beach. Respondents on both the beaches were mostly females (64\%), non-smokers $(75 \%)$ and in their thirties years of age (mean: 37 years of age $\pm S$. $E=0.4$ years). The pattern of permanent residency of people visiting the beaches was distinct. On Mansa beach, $71 \%$ of respondents were from the state capital (Curitiba), whereas in Ipanema beach, this city accounted for $39 \%$.
Visitors from other cities in the Paraná coastal zone accounted for $13 \%$ of respondents in Ipanema beach, compared to $2 \%$ in Mansa beach. These differences were statistically significant (Table 2a; $\chi^{2}=126.5 ; \mathrm{p}<0.001 ; 6$ d.f).

In a similar fashion, educational levels were clearly different for respondents on the two beaches (Table $2 b ; \chi^{2}=140 ; p<0.001 ; 4$ d.f). At Ipanema beach, $46 \%$ of respondents completed only high school, while at Mansa beach this educational level was for $21 \%$ of respondents. Undergraduate studies were completed by $69 \%$ of 
respondents at Mansa beach, which were $36 \%$ of the people interviewed at Ipanema beach.

Monthly income was also a clear factor of distinctiveness between people frequenting the beaches studied (Table 2c; $\chi^{2}=162 ; p<0.001 ; 4$ d.f). Thirty-one percent of respondents from Ipanema beach stated that they earned between US\$263 and 526 per month, whereas this income level was reported by $9 \%$ in Mansa beach. Income greater than US\$2105 per month was mentioned by $44 \%$ of people that were interviewed at Mansa beach and by $12 \%$ of people at Ipanema beach.

Asked about whether or not the beach they were had a problem, 64\% of respondents on Mansa beach and $60 \%$ on Ipanema beach acknowledged problems for those beaches. This difference was not statistically significant $\left(\chi^{2}=1.82 ; p>0.05 ; 1\right.$ d.f.). However, the proportion of eight classes of problems identified by respondents was not similar between the beaches (Fig. 5; $\chi^{2}=32.7 ; p<0.001$; 5 d.f. - two classes were pooled to increase expected frequencies). Problems associated with water quality were mentioned most on both beaches. However, people on Mansa beach mentioned it more than expected. Similarly, the presence of beach debris was the second most mentioned problem on both the beaches, although it was mentioned more than expected at Ipanema beach. The third most mentioned problem on both beaches was associated with the lack of infrastructure, such as public toilets, sidewalks along the beach and illumination. This problem was mentioned more than expected by the respondents from Ipanema beach.

People were asked to state their perception regarding the level of solid waste contamination on the beach they were. Again, results indicated a strong difference between the two beaches studied (Fig. 6; $\chi^{2}=91 ; p<0.001 ; 5$ d.f). The perception that the beach was at a low level of waste contamination was higher than expected at Mansa beach, whereas at Ipanema beach, there were a higher than expected number of answers stating that the beach was at a high level of contamination by solid waste.

Table 2 - Socioeconomic description of respondents. (a) Permanent residency of respondents; (b) Educational level; and (c) Monthly income.

\begin{tabular}{|c|c|c|c|}
\hline & Categories & Mansa Beach $(n=468)$ & Ipanema Beach $(n=546)$ \\
\hline \multirow[t]{6}{*}{ (a) } & Paraná capital city (Curitiba) & $71 \%$ & $39 \%$ \\
\hline & Non-coastal cities in Paraná & $14 \%$ & $34 \%$ \\
\hline & coastal cities in Paraná & $2 \%$ & $13 \%$ \\
\hline & Local municipality & $8 \%$ & $8 \%$ \\
\hline & Other Brazilian states & $4 \%$ & $5 \%$ \\
\hline & Other countries & $1 \%$ & $1 \%$ \\
\hline \multirow[t]{4}{*}{ (b) } & Elementary school & $3 \%$ & $14 \%$ \\
\hline & High school & $21 \%$ & $46 \%$ \\
\hline & Undergraduate studies & $69 \%$ & $36 \%$ \\
\hline & Graduate studies & $7 \%$ & $4 \%$ \\
\hline \multirow[t]{5}{*}{ (c) } & Less than US\$ 263 & $2 \%$ & $7 \%$ \\
\hline & Between US\$ 263 and US\$ 526 & $9 \%$ & $31 \%$ \\
\hline & Between US\$ 526 and US\$ 1052 & $15 \%$ & $29 \%$ \\
\hline & Between US\$ 1052 and US\$ 2105 & $30 \%$ & $21 \%$ \\
\hline & More than US\$ 2105 & $44 \%$ & $12 \%$ \\
\hline
\end{tabular}




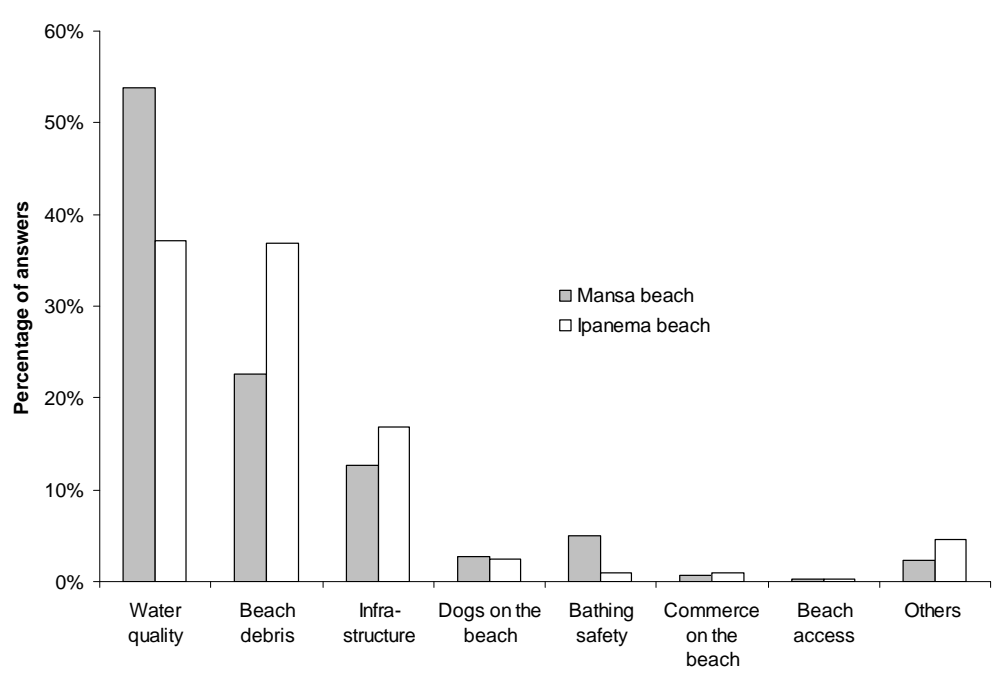

Figure 5 - Percentage of answers according to classes of problems identified by beachgoers on the beaches studied.

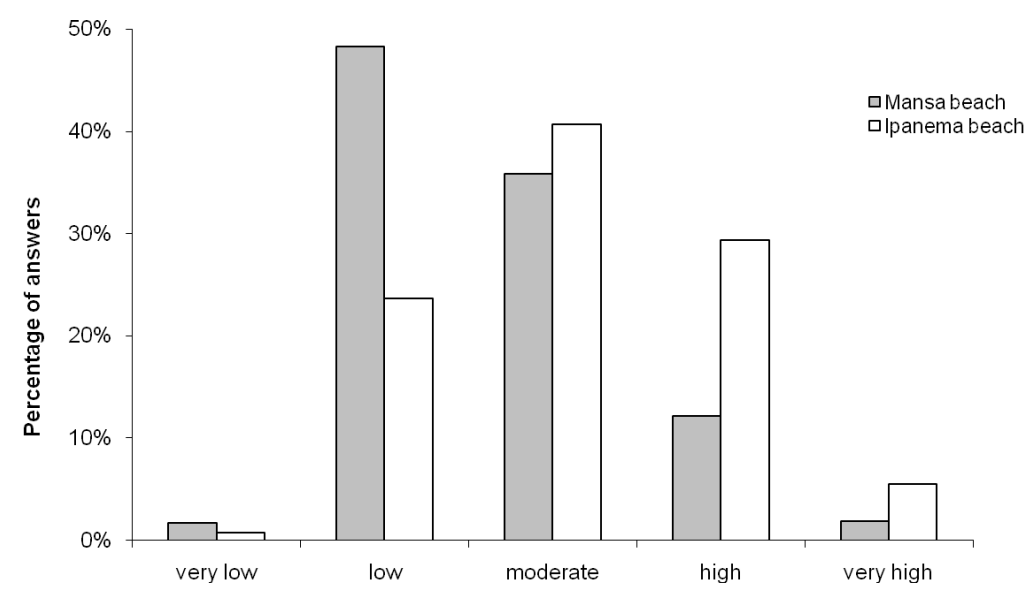

Figure 6 - Percentage of answers relative to the perceived level of solid waste contamination on studied beaches.

On both the beaches, respondents mostly indicated beachgoers as being responsible for the presence of solid waste on the beach (Fig. 7). The second most cited responsible for the existence of litter on the beach was the inertia of the local government on both the beaches. The pattern of answers between the two studied beaches was not statistically significant $\left(\chi^{2}=4.2 ; p>0.05 ; 3\right.$ d.f).

Next, people were asked how often they themselves left the debris on the beach. On both the beaches, the majority of respondents said they never abandon litter on the beach (Fig. 8). However, a greater than expected proportion of respondents from Ipanema beach acknowledged that they rarely left litter on the beach $\left(\chi^{2}=25.5 ; \mathrm{p}\right.$ $<0.001 ; 3$ d.f).

Regarding how often people left the debris on the beach, smokers and non-smokers displayed a distinct pattern of answers. A larger than expected proportion of smokers acknowledged that they always or frequently left the litter on the beach, including cigarette stubs. Conversely, a smaller than expected proportion of smokers stated that they never left cigarette stubs or other litter items on the beach. These differences were statistically significant $\left(\chi^{2}=25.9 ; p<0.001 ; 3\right.$ d.f. 


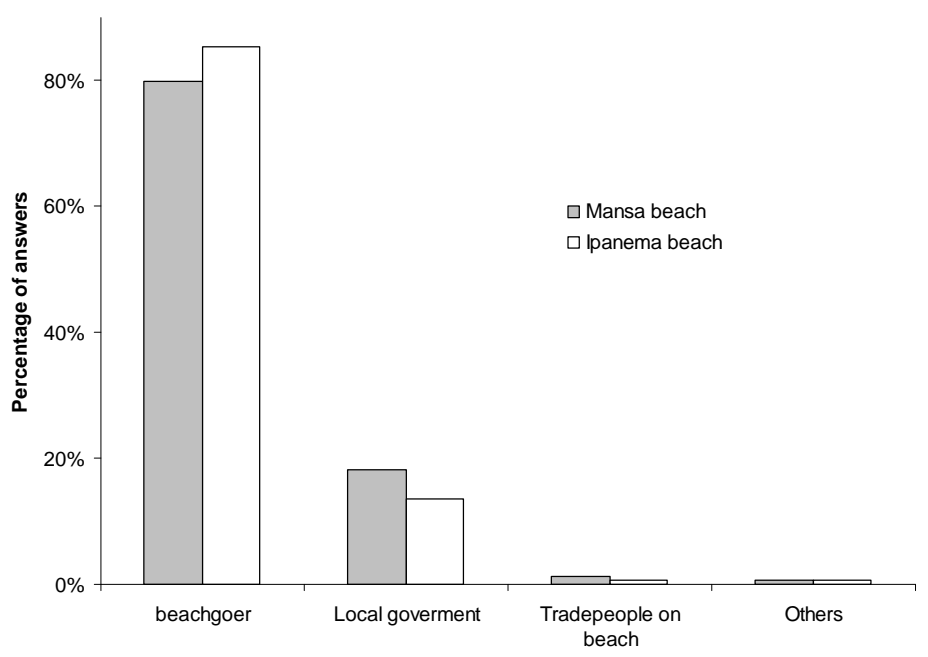

Figure 7 - Percentage of answers relative to the main responsible for the presence of solid waste on beaches, as stated by respondents on two beaches.

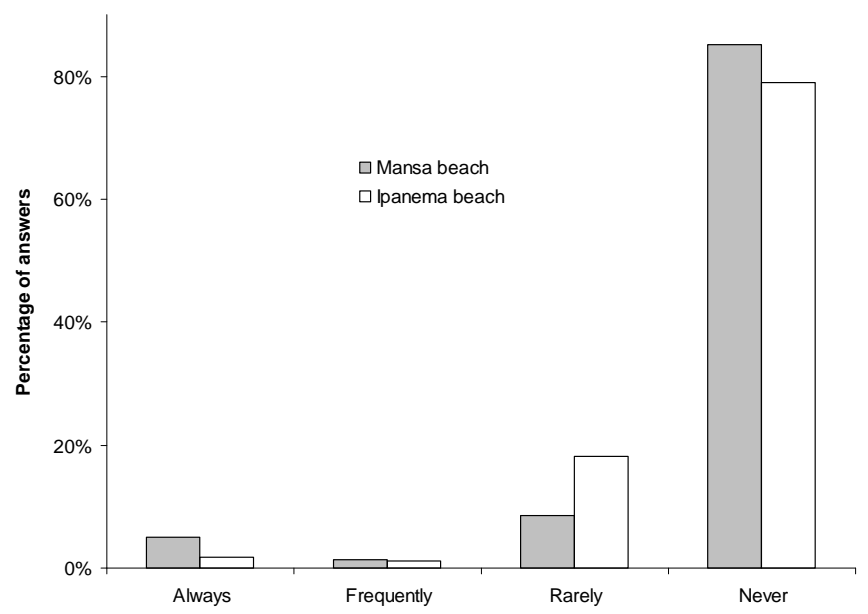

Figure 8 - Percentage of answers according to stated frequency of abandonment of solid waste on beach by beachgoers interviewed on two beaches.

\section{DISCUSSION}

Contrary to what was hypothesized, the results of this study indicated that the percentage of abandonment of PBA was small (less than 5\%). This suggested that the distribution of PBA represented a small risk of beach contamination due to the presence of the very PBA being abandoned by beachgoers.

The expectation of a large number of abandoned PBA was based on the observation that other materials distributed on the beaches, such as folders and plastic bags, were frequently left on the beach. It was also based on the statement by Santos et al.'s (2005) that "In southern Brazilian beaches, the distribution of advertisement folders and plastic bags for keeping litter out of beaches is very common. However, this was often observed as just other source of litter to the beach". In Boa Viagem beach (Pernambuco, Brazil), pamphlets were identified as flag items due to their abundance and because they could be "(...) directly and surely related to the beach user and gravely affecting the aesthetics of the beach, (...)" (Silva et al., 2008). 
This study suggested that the typical behavior of leaving on the beach material that was distributed to beachgoers did not hold for the particular case of PBA. One possible explanation for this unexpected result was that a PBA could be perceived as something new, associated with a special character, different than more trivial leaflets and folders distributed on beaches. It was possible that PBA was perceived as something environmentally friendly and the beachgoers cared more about them, resulting in a behavior that led to a small percentage of abandonment.

There is no known regulation regarding the distribution of promotional material on Brazilian beaches. However, one can assume that under the precautionary principle, the distribution of PBA without an assessment of its detrimental effects on the environment is inadequate. Therefore, this result could have a managerial implication, since it provided objective information which allows coastal managers to make wiser decisions about the use of this equipment. Ideally, studies such as this one should be performed before the widespread distribution of material on the beaches.

There was no identifiable difference in the abandonment pattern regarding the two beaches studied, although these beaches were frequented by people with distinct socioeconomic profiles. Again, it was possible to speculate that on both the beaches PBA were perceived as something special, leading to a more careful behavior, irrespective of the socioeconomic profile of the people visiting these beaches. However, this proposition must be taken with caution, because the mean percentage of abandonment at Praia Mansa was three times greater than at Ipanema beach. Therefore, it was possible that a true difference between percentages of abandonment associated with different socioeconomic profiles might not have been detected due to the use of a statistical test that is nonparametric (i.e., less powerful) and that was based on the samples with a small number of replicates $\left(\mathrm{n}_{1}=7\right.$ and $\left.\mathrm{n}_{2}=8\right)$.

Contrary to the proposed hypothesis, cigarette stubs represented less than $50 \%$ of the contents of a large number of PBA. However, and possibly more importantly, the mean abundance of cigarette stubs was significantly greater than the abundances of the other types of materials found in the PBA. Furthermore, there were several PBAs that contained cigarette stubs only. These results suggested that PBA contributed to the prevention of cigarette stubs (and, to a lesser degree, of other types of litter) being left on the sand of beaches. Since there were, on average, 3.44 cigarette stubs in each returned PBA, one could assume that the distribution of 1,500 PBA in a summer season (30 days) accounted for the prevention of 154,800 cigarette stubs contaminating Paraná beaches. This could be relevant, since the presence of cigarette stubs on the beaches is a problem widely reported (e.g. Cunningham and Wilson, 2003; Santos et al., 2005; Silva-Iñiguez and Fisher, 2003; Tudor et al., 2002; Tudor and Williams, 2004; Wetzel et al., 2004).

Beyond the aesthetics problem, each cigarette stub holds tar, cadmium, lead and arsenic, which may be toxic to some organisms and may enter food webs (Register, 2000). Therefore, the results obtained in this study could allow the managers to make informed decisions in terms of how many PBA would be necessary in order to achieve a defined level of contamination reduction.

Plastics items were the second most abundant material in the PBA. This was important because plastic items could be ingested by animals such as seabirds (Barbieri, 2009). Many invertebrates present on beach environments (e.g. Barros et al., 2001) may also ingest small plastic fragments. The ecological consequences of the entrance of plastics in marine food webs are still unclear.

This study also identified a clear distinction between the socioeconomic profiles of people visiting the two beaches. People visiting Mansa beach were mainly wealthy urbanites that held a university degree. In contrast, many people that visited Ipanema beach came from non-coastal cities in Paraná other than the state capital. Many of them did not hold a university degree and their monthly income was typically smaller than people that frequented Mansa beach.

There were clear distinctions between the perceptions of beachgoers on both the beaches regarding environmental issues. Relative to people interviewed at Ipanema beach, beachgoers at Mansa beach were less concerned about the beach debris and believed that that beach was at a lower level of solid waste contamination. In addition, fewer of them stated that they "rarely" abandoned litter on the beach. It was possible, therefore, that socioeconomic characteristics of the people on the beach influenced their perceptions about the level of solid waste contamination. It was also possible, however, that a true difference in the levels of contamination of these two beaches was 
responsible for the differences in the perceptions observed.

It would be important to mention, however, that some other differences in perceptions were not statistically significant. Therefore, the role of socioeconomic characteristics in explaining environmental perceptions was partial.

The observed differences regarding the socioeconomic characteristics of the two groups of beachgoers and regarding their perceptions about beach debris suggested support for the proposed hypothesis that a relationship between these two factors was a general pattern. This suggestion gained robustness when one considered another study in south Brazil that found similar results (Santos et al., 2005).

One result that was consistent on both the beaches was the understanding that beach visitors were the prime responsible group for the presence of debris on the beaches. It was interesting to note that the majority of respondents on both the beaches also stated that they "never" abandoned litter on the beach. It seemed, therefore, that beach visitors typically took the comfortable position of saying that the presence of litter on the beach was due to the misbehavior of all other beach users except $\mathrm{him} / \mathrm{her}$. This suggested the pertinence of an educational campaign for raising the selfconsciousness level of beach users, in terms of their environmental attitudes.

The international Blue Flag program of beach certification is currently being implemented in Brazil (Scherer, 2006). The amount of debris present on a beach will be used as one criterion for Blue Flag certification of Brazilian beaches. The Brazilian program of waterfront management (Projeto Orla, 2002) also uses information about the level of solid waste contamination in order to classify sectors of the waterfront. Therefore, studies that contribute to the increment of understanding about the problem of beach debris are necessary, because this knowledge can be used by the managers. This experimental study is an example of how hypothesis-driven science can contribute to the objective evaluation of environmental decision-making. Hopefully, Brazilian coastal managers will use this sort of information to make wiser decisions regarding the problem of beach debris.

\section{ACKNOWLEDGEMENTS}

Authors thank Larissa Sadoski and Lívia Giordano for performing field and laboratory work with responsibility and competence and to Dr Marinez Scherer who commented the original version of the manuscript.

\section{RESUMO}

A presença de resíduos sólidos no ambiente marinho é extensa. Praias são tipicamente contaminadas com esses materiais, que podem causar impactos ecológicos. Resíduos sólidos nas praias podem causar ferimentos nas pessoas e podem prejudicar a atividade turística. Neste estudo, hipóteses relativas ao uso de cinzeiros de praia foram testadas. Os resultados indicam que a taxa de abandono desse equipamento é pequena $(1,5 \%)$ e que a quantidade média de pontas de cigarro (3,4 itens/cinzeiro) é maior do que as quantidades médias de outros tipos de lixo. Também se observou que pessoas com diferentes perfis socioeconômicos apresentaram percepções diferentes relativas à presença de resíduos sólidos nas praias. Estes resultados sugerem que cinzeiros portáteis podem ser um equipamento importante na redução da contaminação das praias e que diferenças socioeconômicas dos freqüentadores das praias podem explicar parcialmente as diferentes percepções relativas à presença de resíduos no ambiente praial. Sugere-se que os gerentes costeiros usem esse tipo de informação para planejar estratégias de redução desse problema.

\section{REFERENCES}

Angulo, R. J. (2004), Mapa do Cenozóico do litoral do estado do Paraná. Boletim Paranaense de Geociências 55, 24-42.

Barbieri, E. (2009), Occurence of plastic particles in Procellariiforms, South of São Paulo State (Brazil). Brazilian Archives of Biology and Technology 52 (2), 341-348.

Barros, F.; Borzone, C. and Rosso, S. (2001), Macroinfauna of six beaches near Guaratuba Bay, Southern Brazil. Brazilian Archives of Biology and Technology 44 (4), 351-364. 
Byrkit, D. R. (1987), Statistics today - a comprehensive introduction. Benjamin-Cummings Publishers. Massachusetts (USA).

CleanBeach (2009), CleanBeach Consciência Ecológica web site: http://www.cleanbeach.com.br. Accessed on 29/06/2009.

Corbin, C. J. and Singh ,J. G. (1993), Marine debris contamination of beaches in St. Lucia and Dominica. Marine Pollution Bulletin. 26(6), 325-328.

Cordeiro, C. and Costa, T. (2007), Avaliação dos resíduos sólidos retidos nas franjas de manguezais de São Vicente, SP, Brasil. Paper presented at XII Congresso Latino Americano de Ciências do Mar COLACMAR. Florianópolis, 15 a 19 de abril de 2007. Associação Brasileira de Oceanografia.

Cunningham, D. and Wilson, S. (2003), Marine debris on beaches of the Greater Sydney region. Journal of Coastal Research 19(2), 421-430.

Ivar do Sul, J. and Costa, M. F. (2007), Marine debris review for latin America and the wider Caribbean region: from the 1970's until now and where do we go from here? Marine Pollution Bulletin 54, 1087 1104.

Madzena, A. and Lasiak, T. (1997), Spatial and temporal variations in beach litter on the Transkei Coast of South Africa. Marine Pollution Bulletin 34 (11), 900-907.

Novotny, T. E. and Zhao, F. (1999), Consumption and production waste: another externality of tobacco use. Tobacco Control., 8, 75-80.

Projeto Orla (2002), Projeto Orla - manual de gestão. Ministério do Meio Ambiente e Ministério do Planejamento, Orçamento e Gestão. Brasília.

Register, K. M. (2000). Cigarette butts as litter - toxic as well as ugly. Underwater Naturalist - Bulletin of the American Littoral Society 25 (2), 23-29.

Santos, I.; Friedrich, A. and Duarte, E. (2003), Percepções sobre o lixo na praia do Cassino (RS, Brasil). Mundo and Vida 4 (1).

Santos, I.; Friedrich, A.; Wallner-Kersanach, M. and Fillmann, G. (2005), Influence of socio-economic characteristics of beach users on litter generation. Ocean and Coastal Management 48, 742-752.

Scherer, M. (2006), Blue Flag: A program of environmental certification of beaches contributing for the Brazilian policy of coastal management. Gestão Costeira Integrada 5 (4), 49-51.

Silva-Iniguez, L. and Fisher, D. W. (2003), Quantification and classification of marine litter on the municipal beach of Ensenada, Baja California, Mexico. Marine Pollution Bulletin., 46, 132-138.
Silva, J.; Barbosa, S. and Costa, M. (2008), Flag items as a tool for monitoring solid wastes from users on urban beaches. Journal of Coastal Research 24 (4), 890-898.

Tudor, D.; Williams, A.; Randerson, P.; Ergin, A. and Earll, R. (2002), The use of multivariate statistical techniques to establish beach debris pollution sources. Journal of Coastal Research, SI 36, 716-725.

Tudor, D. and Williams, A. (2004), Development of a 'Matrix Score Technique' to determine litter sources at a Bristol Channel beach. Journal of Coastal Conservation., 9, 119-127.

Underwood, A. J. (1997), Experiments in ecology their logical design using analysis of variance. Cambridge University Press, Cambridge (UK).

Underwood, A. J. (1998), Relationships between ecological research and environmental management. Landscape and Urban Planning., 40 (1-3), 123-130.

Wetzel, L., Fillmann, G, and Nienchesky, L. (2004), Litter contamination on the Brazilian southern coast: Processes and management perspectives. International Journal of Environment and Pollution., 21, 153-164.

Widmer, W. M. (2004), Recreational boats and submerged marine debris in Sydney Harbour, Australia. In: Recent Advances in Marine Science and Technology 2002, ed. N. Saxena. PACON International, Honolulu, pp. 565-575.

Widmer, W. M.; Soriano-Sierra, E.; Hennemann, M. and Carrero, G. (2004), Patterns of marine debris on sandy beaches on the island of Santa Catarina, South Brazil. Paper presented at II Simpósio Brasileiro de Oceanografia. Instituto Oceanográfico da Universidade de São Paulo.

Widmer, W. M. (2009), The importance of the experimental approach to the advance of integrated coastal management. Journal of Integrated Coastal Zone Management., 9 (1), 7-16.

Williams, A. T. and Nelson, C. (1997), The public perception of beach debris. Shore and Beach., 65 (3), $17-20$.

Received: February 11, 2009; Revised: June 10, 2009; Accepted: December 12, 2009. 